\title{
Modern Perspectives on Fiscal Stabilization Policies *
}

\author{
Jordi Galí \\ CREI and Universitat Pompeu Fabra
}

August 2005

(first draft: May 2004)

\begin{abstract}
The present paper describes recent research on two central themes of Keynes' General Theory: (i) the social waste associated with recessions, and (ii) the effectiveness of fiscal policy as a stabilization tool. The paper also discusses some evidence on the extent to which fiscal policy has been used as a stabilizing tool in industrial economies over the past two decades.
\end{abstract}

JEL Classification no.: E32, E63

Keywords: business cycles, inefficient allocations, government spending multiplier, non-Ricardian households, countercyclical policies.

\footnotetext{
* Revised version of the keynote lecture given at the CESifo Workshop on "The Revival of Aggregate Demand Management Policies: Back to Keynes?,” Venice, 19-20 July 2004. Earlier versions circulated under the title "Modern Perspectives on Stabilization Policies." I am grateful to co-editor Roel Beetsma and an anonymous referee for comments and suggestions, and to Anton Nakov for excellent research assistance. Much of the material in the present paper is based on my earlier work with Mark Gertler, David López-Salido and Roberto Perotti, all of whom contributed decisively to the development of the ideas contained herein. Correspondence: CREI, Ramon Trias Fargas 25, 08005 Barcelona (Spain). E-mail: jordi.gali@upf.edu
} 


\section{Introduction}

The purpose of the present paper is to describe some recent research on two themes that have a strong Keynesian flavor: (i) the social waste associated with recessions, and (ii) the effectiveness of fiscal policy as a stabilization tool. Keynes analysis of both themes constitutes the core of the General Theory and, arguably, his most enduring contribution to economics.

As part of the recent revival of Keynesian macroeconomics, some authors have revisited both themes, taking advantage of the tools and concepts that have been developed and adopted in recent years. In the present paper I summarize some my own recent research on the costs of recessions and the stabilizing role of fiscal policy in the postwar period. The basic argument of the paper can be summarized as follows.

- Recent empirical evidence suggests that business cycle fluctuations are associated with large variations in the degree of aggregate efficiency in the economy or, in other words, in the distance to "first-best". That evidence is summarized in section 2.

- The presence of large efficiency gaps in periods of recession justifies the pursuit of countercyclical fiscal policies, with government spending being set at a level above that warranted by "efficient provision of public goods" considerations. 
Section 3 develops a simple analytical framework which justifies the pursuance of countercyclical fiscal policies in a world in which recessions are associated with declines in aggregate efficiency.

- The empirical evidence points to the adoption of increasingly countercyclical policies by governments in OECD countries over the postwar period, as shown in section 4. In light of the arguments made in section 3, such trends in fiscal policy should be welcome.

Next I discuss each of the three themes in turn.

\section{A New-Keynesian Perspective on the Welfare Costs of Business Cycles}

In broad terms, and at the risk of oversimplification, one can think of two competing views of the business cycle. The first view, which I will refer to as neoclassical, is best exemplified in our days by Real Business Cycle (RBC) theory. Under that view, business cycles can be interpreted as the economy's optimal response to shocks, at least to a firstorder approximation. While some inefficiencies and distortions may be present in the economy, they are not viewed as central to cyclical phenomena. Most importantly, public 
authorities' efforts at stabilization may be counterproductive, and could even reduce welfare. ${ }^{1}$

An alternative view of business cycles, which I will label as Keynesian, interprets recessions as periods in which the utilization of productive resources is inefficiently low, while expansions are viewed as times when the level of economic activity approaches its social optimum. Thus, according to this second view, business cycles are associated in a fundamental way with variations over time in the efficiency of aggregate resource allocations.

In recent work with Mark Gertler and J. David López-Salido² (GGL, henceforth) we have developed a framework that seeks to provide a quantitative assessment of the relevance of the Keynesian view of the cycle. Our starting point is a measure of distance between an economy's activity level and the efficient one. That measure, which we refer to as "the gap" takes the following form:

$$
g a p_{t}=m r s_{t}-m p n_{t}
$$

where $m r s_{t}$ denotes the (log) marginal rate of substitution between consumption and leisure, and $m p n_{t}$ is the (log) marginal product of labor (or, equivalently, the marginal rate of transformation between consumption and hours). The efficient level of economic activity is implicitly determined by the condition gap $_{t}=0$. The presence of distortions of different sorts (market power, distortionary taxes) will generally imply that the gap

\footnotetext{
${ }^{1}$ Prescott (1986) constitutes a classical reference for an exposition of the neoclassical view.

${ }^{2}$ Galí, Gertler, and López-Salido (2005)
} 
variable takes a negative value (corresponding to an inefficiently low level of economic activity).

As shown in GGL, given a parametric specification for the marginal product of labor and the marginal rate of substitution, it is possible to construct a measure of the gap or, to be more precise, of its fluctuations around its mean. The reader will find a derivation of that measure in Appendix A to the present paper. GGL's analysis of the time series properties of the resulting measure points to two key properties of the gap variable for the postwar U.S.: (i) a high volatility, with a standard deviation that is systematically larger than the one for conventional output gap measures, and (ii) a high positive correlation with conventional measures of the output gap. Those findings are illustrated in Figure 1, which displays the time series for GGL's gap variable (under GGL's baseline assumptions). In particular, we see how NBER-dated recessions, which are represented by the vertical grid lines, correspond to periods of large declines in the gap variable.

The combination of the two findings described above can be interpreted as providing favorable evidence for the Keynesian view of business cycles: they point to large fluctuations in the degree of inefficiency in the aggregate allocation of resources, and suggest a systematic relationship of those fluctuations with the business cycles, with recessions corresponding to periods with unusually large aggregate inefficiencies.

GGL show that the gap variable can be written as (minus) the sum of two components. The first component, denoted by $\mu_{t}^{p}$ represents the wedge between (log) 
labor productivity and the (log) real wage, and has the natural interpretation of an average price markup, i.e. a measure of the deviation from perfect competition in goods markets. The second component, denoted by $\mu_{t}^{w}$ is the difference between the (log) real wage and the (log) marginal rate of substitution, and can thus be thought of as a labor market wedge measure, reflecting distortions in that market (including non-competitive wage setting, as well as labor income and payroll taxes). As shown in appendix A, and given our gap definition, it follows by construction that

$$
\operatorname{gap}_{t}=-\left(\mu_{t}^{p}+\mu_{t}^{w}\right)
$$

Accordingly, and given the findings mentioned above, recessions must be associated, at least on average, with a higher wedge in goods markets, labor markets, or both. While the work of Rotemberg and Woodford (1999), among others, had already stressed the countercyclical nature of price markups, the empirical analysis in GGL points to much larger variations in the labor market wedge, which appears to be the dominant source of fluctuations in the gap variable. That evidence suggests that recessions correspond to periods in which real wages are too high relative to the opportunity cost of working.

The previous evidence raises an interesting issue closely connected with Keynes’ own perspective on the nature of recessions. It is clear that the well documented rigidity of nominal wages, together with the non-Walrasian nature of contractual relationships between workers and firms, may explain why real wages are so much higher than the marginal rate of substitution in downturns. Yet, it does not follow from that observation that making real wages fully flexible and, in the limit, restoring perfect competition in 
labor markets would suffice to restore a first best allocation. The reason is simple: to the extent that the enhanced wage flexibility is not accompanied by an increase in the level of economic activity that brings about an increase in the marginal rate of substitution (and/or a decrease in the marginal product of labor), the decline in the labor market wedge will just be offset by an increase of equal size in the average price markup. But in a world where firms do not perceive the demand for their goods as being perfectly elastic, the only way to increase economic activity and hours worked (and, as a result, to reduce aggregate inefficiencies) is for aggregate demand to increase. But that increase in aggregate demand will not be brought about mechanically by the lower wages; instead it may require that appropriate fiscal and monetary policies are undertaken to guarantee that a higher level of activity is attained. ${ }^{3}$

What are the welfare consequences of fluctuations in the gap variable? As shown in GGL the second order approximation to the utility gains or losses resulting from fluctuations in the gap variable takes the form:

$$
U_{t}-U=\alpha \widehat{\operatorname{gap}}_{t}-\beta \widehat{\operatorname{gap}}_{t}^{2}
$$

\footnotetext{
${ }^{3}$ In Keynes’ own words: “...there is no reason in general for expecting [the level of employment] to be equal to full employment. The effective demand associated with full employment is a special case, only realized when the propensity to consume and the inducement to invest stand in a particular relationship to one another. This particular relationship, which corresponds to the assumptions of the classical theory...can only exist when by accident or design, current investment provides an amount of demand just equal to the excess of [income] over what the community will choose to spend on consumption when it is fully employed” [Keynes (1936), p. 28]
} 
where $\widehat{g a p}_{t} \equiv g a p_{t}-$ gap denotes the (log) deviation of the gap variable from its steady state value, and where both $\alpha$ and $\beta$ are positive coefficients which are in turn a function of underlying primitive parameters.

The previous discussion, based on GGL's analysis, has two natural implications for the design of macroeconomic policy. First, it provides a theoretical justification for countercyclical policies, at least to the extent that the business cycle involves fluctuations in the degree of efficiency of the aggregate allocation of resources. Yet, as it is clear from the expression above the gains from stabilizing the gap variable are of second order. Thus, GGL estimate those gains to be always below one-tenth of one percent of annual consumption, for the range of calibrations considered.

The previous analysis, however, conceals an aspect of economic fluctuations that can have potentially important implication for the design of macroeconomic policy, potentially justifying activist countercyclical fiscal policies. The next section formalizes the previous idea, using a highly stylized aggregative model of optimal fiscal policy determination.

\section{A Case for Countercyclical Fiscal Policy}

The analysis of the gap variable and its fluctuations has an important additional dimension related to welfare that is worth emphasizing here. In a nutshell, the fact that 
fluctuations take place around a distorted (i.e., inefficient) steady state or balanced growth path implies that expansions and recessions will generally have first-order effects on welfare. To the extent that an increase in government purchases has an expansionary effect on the economy, there will be an incentive to raise that variable beyond what would be justified by a criterion based strictly on the efficient provision of public goods. Furthermore, to the extent that the degree of aggregate inefficiency is larger in recessions than in expansion (as the evidence summarized above would suggest), the incentive to raise government purchases will vary with the cycle, leading an optimizing government to pursue a countercyclical fiscal policy.

The previous point can be illustrated by considering a highly stylized aggregative economy with preferences represented by the period utility

$$
U\left(C_{t}, N_{t}, G_{t}\right)
$$

and with a resource/market clearing constraint given by

$$
Y_{t}=C_{t}+G_{t}
$$

The effect on current utility of an increase in government purchases is given by

$$
\begin{aligned}
\frac{d U_{t}}{d G_{t}} & =U_{C, t}\left(\frac{d Y_{t}}{d G_{t}}-1\right)+U_{G, t}+U_{N, t} \frac{d N_{t}}{d Y_{t}} \frac{d Y_{t}}{d G_{t}} \\
& =U_{C, t} \frac{d Y_{t}}{d G_{t}}\left(1-\exp \left\{\operatorname{gap}_{t}\right\}\right)+\left(U_{G, t}-U_{C, t}\right)
\end{aligned}
$$

By equating the previous expression to zero we can derive an implicit optimal rule for the level of government spending: 


$$
U_{G, t}=U_{C, t}\left(1-\frac{d Y_{t}}{d G_{t}}\left(1-\exp \left\{g a p_{t}\right\}\right)\right)
$$

Hence, to the extent that (i) the level of economic activity is inefficiently low $\left(\operatorname{gap}_{t}<0\right)$, and (ii) the government spending multiplier is positive $\left(d Y_{t} / d G_{t}>0\right)$, the optimal fiscal policy satisfies

$$
U_{G, t}<U_{C, t}
$$

We see thus that the optimal level of government purchases will remain above that associated with the simple criterion for the optimal provision of public goods, which in the stylized model above would require that the marginal utility of public and private consumption are equated. The reason is straightforward: in addition to satisfying the demand for public goods, government purchases can be used to increase employment, thus reducing the welfare losses resulting from an inefficiently low level of activity.

It is also clear from expression (2) that the incentive to raise government spending will be greater the larger is the multiplier $d Y_{t} / d G_{t}$ and the lower (i.e., the more negative) is the gap $_{t}$ variable. ${ }^{4}$ Hence, and given a positive multiplier, the evidence of a highly procyclical behavior of the gap variable provided in the previous section would call for a countercyclical fiscal policy, i.e. increases in government spending in recession times (low gap), with spending cuts in periods of expansion.

\footnotetext{
${ }^{4}$ Models in the RBC tradition often predict relatively low government spending multipliers, as a consequence of crowding-out effects on consumption. Nevertheless, the introduction of non-Ricardian households, who consume their current income as opposed to their permanent income, combined with deficit financing can raise that multiplier dramatically, as shown in Galí, López-Salido and Vallés (2004).
} 
How about taxes? While not formalized explicitly above, it is clear that distortionary taxes must be an important source of the efficiency gap. A simple way to represent that connection is to think of the gap variable as having two components: one related to (income) taxes and a second incorporating all other sources of gap variation (e.g., "pure” markups). In that context we would expect an optimizing government to use tax policy to reduce gap fluctuations. Thus if a decline in the gap occurs as a result of the higher markups induced, say, by the combination of an adverse demand shock and the presence of nominal rigidities, the government could in principle dampen the drop in the gap (and its first-order negative welfare effects) by lowering the tax rate transitorily and issuing debt, while waiting for an expansionary period to raise taxes again. If one combines that prescription for tax policies with the case for countercyclical government spending made above, it seems plausible to conclude that in an economy characterized by a distorted steady state and fluctuations in the efficiency gap, countercyclical government deficits should be desirable. Interestingly, and as described in the next section, governments in industrialized countries appear to have followed that prescription with increasing zeal over the past decades.

\section{Some Evidence on the Role of Fiscal Policy as a Source of Increasing Macroeconomic Stability}

Much recent empirical evidence points to a substantial decline in GDP volatility among industrialized countries over the past half-century. ${ }^{5}$ Some of the explanations put

\footnotetext{
${ }^{5}$ See, e.g. the surveys by Stock and Watson $(2002,2003)$.
} 
forward in order to account for that phenomenon are structural in nature: shift from goods to services, improvements in inventory management, better access to financial markets, etc. Several authors have pointed to smaller exogenous shocks (i.e. good luck) as a dominant factor. Finally, other authors have stressed the role of improved macroeconomic policies.

In the present section I summarize some of the findings contained in a recent paper by Roberto Perotti and myself (henceforth, GP), which shed some light on one particular dimension of that debate, namely, the changing role of discretionary fiscal policy as a stabilizing factor. ${ }^{6}$ While the main objective of GP was to provide an assessment of the extent to which the constraints associated with the Maastricht Treaty and the Stability and Growth Pact affected in practice the way European governments have conducted fiscal policy, our work also shed some light on the evolution of discretionary fiscal policy for a broader set of countries. In particular, we use annual data for the period 1980-2002 for eleven EMU countries (all current members less Luxembourg), three non-EMU members of EU (UK, Denmark, and Sweden; henceforth, the EU3), and five non-EU countries (Norway, Japan, Australia, Canada, and the United States; henceforth, OECD5), and estimate a fiscal policy rule of the form

$$
d_{t}^{*}=\phi_{0}+\phi_{x} E_{t-1}\left\{x_{t}\right\}+\phi_{b} b_{t-1}+\phi_{d} d_{t-1}^{*}+u_{t}
$$

where $d_{t}^{*}$ is the cyclically adjusted (or structural) deficit for year $t$ (measured as a share of potential GDP), $E_{t-1}\left\{x_{t}\right\}$ is the year $t-1$ forecast of output gap for year $t$ (i.e., the percent deviation of GDP from potential), and $b_{t-1}$ is the amount of outstanding debt

\footnotetext{
${ }^{6}$ See Galí and Perotti (2003)
} 
(relative to potential GDP) in period $t-1$. The use of the output gap forecast and the lag of the debt/GDP ratio in the above specification implicitly (and realistically) assumes that decisions on the discretionary component of the budget have largely been made by the end of the previous year. Notice that a negative value of $\phi_{x}$ indicates that policymakers use discretionary fiscal policy in a systematic countercyclical way: when cyclical conditions are expected to improve (i.e., when the output gap forecast rises), discretionary fiscal policy becomes more restrictive -- the structural deficit falls. To estimate the above fiscal policy rule, GP replace $E_{t-1}\left\{x_{t}\right\}$ with $x_{t}$, and instrument the latter using $x_{t-1}$ and the lagged value of the US output gap (the lagged EU15 output gap for the US).

Table 1 reports estimates of $\phi_{x}$ for each group of countries (EMU, EU3, and OECD5), drawn from the GP paper. The top panel shows averages of country-specific $\phi_{x}$ estimates, while the bottom panel displays the corresponding estimates based on a panel regression. ${ }^{7}$ The picture that emerges is reasonably similar for both sets of estimates. With the exception of EMU countries in the first half of the sample, the evidence points to the existence of a systematic countercyclical discretionary fiscal policy, reflected in the negative estimates for $\phi_{x}$. Most interestingly, however, for the three sets of countries the GP estimates identify a substantial increase in the absolute value of $\phi_{x}$, thus suggesting a much stronger response of fiscal policy to cyclical developments, in a stabilizing direction. The previous evolution is particularly relevant for current EMU countries,

\footnotetext{
${ }^{7}$ Details can be found in Galí and Perotti (2003).
} 
whose fiscal policy was on average procyclical before 1992, becoming countercyclical only in the second half of the sample (and despite the constraints associated with Maastricht and the SGP).

Table 2 reports similar evidence obtained by GP, but now focusing on recessions, and the strength with which governments have used discretionary policy to fight them. The starting point of the exercise consists of identifying for each country the years in which its output gap experiences a decline, during the three main global recession waves of the early 80 s, the early 90 s, and the early 2000s. For each group of countries and recession episodes Table 2 shows the (average) ratio between (i) the cumulative change in the structural deficit (measured as a share of GDP) over the recession period, and (ii) the cumulative change in the output gap over the same period. Since the latter is negative by construction, an increase in the structural deficit during the recession (i.e., a countercyclical policy response) corresponds to a negative value for the ratio reported. In addition the size of the ratio gives us an indication of the intensity of the discretionary fiscal response to each recession episode.

The picture that emerges from that exercise is consistent in many dimensions with the evidence discussed above, though some qualifications seem relevant. In particular, we see how, for the three sets of countries considered, the behavior of discretionary fiscal policy during recessions has made a transition from being somewhat procyclical to becoming countercyclical. On average, non-EMU countries seem to have experienced that transition in the early nineties. EMU countries, on the other hand, kept largely procyclical policies 
during the recession of the early 90s, which undoubtedly must have contributed to the size and persistence of the latter.

Overall the findings reported in GP and summarized above show little evidence that Maastricht and SGP-related constraints may have significantly impaired in practice the stabilizing role of fiscal policy in EMU countries. If anything, the evidence reported in tables 1 and 2 suggests the opposite: it points to the disappearance in the post-Maastricht period of the significant pro-cyclicality that characterized (on average) the fiscal policy of EMU countries in the previous decade. That development is consistent with what appears to be a global trend towards more countercyclical fiscal policies. Interestingly, however, EMU countries seem to lag behind the rest of OECD countries in terms of that trend.

The evidence on fiscal policy described above complements some of the findings in the recent literature on empirical interest rate rules. That literature points to a significant role of monetary policy in the attainment of low and steady inflation and milder economic fluctuations, two features that have characterized the past two decades in much of the industrialized world. ${ }^{8}$ The evidence in GP, summarized above, suggests that the improvement in the conduct of economic policies has not been restricted to the monetary arena: fiscal policy in much of the industrialized world seems to have left behind the days when it was a likely source of enhanced volatility, and may have instead become a stabilizing force.

\footnotetext{
${ }^{8}$ See,e.g., Clarida, Galí, and Gertler (2000) and Taylor (1999).
} 


\section{Concluding Remarks}

At the risk of oversimplification, one may summarize the theme underlying much of that the new Keynesian research program as follows: Keynes and his followers got it right, but they just did not have the tools. What Keynes "got right" was the notion that the fluctuations in the level of economic activity that we observe in industrial economies--

and, most prominently, the recurrent episodes of recession and high unemployment—are, to some extent, undesirable and avoidable and that policy can be effective in limiting their negative effects. What Keynes did not have were the analytical tools that are available to us now and, in particular, the flexible dynamic general equilibrium (DGE) models that are at the heart of much recent research on optimal policy in the presence of frictions of all sorts. The interest that such research has raised in policy institutions like the ECB, the Federal Reserve or the IMF (which are developing their own DGE models with nominal rigidities) suggests that we may be getting closer to establishing a strong connection between economic theory and macroeconomic policy. 


\section{APPENDIX A}

For concreteness, and following GGL's baseline specification, consider a simple economy where the marginal product of labor is given (up to a constant term) by $m p n_{t}=y_{t}-n_{t}$, where $y_{t}$ denotes output and $n_{t}$ is hours worked, both expressed in logs and normalized by the size of the working age population. Such a relationship is consistent with a conventional Cobb-Douglas production function. Let us assume, on the other hand, that the (log) marginal rate of substitution is given by $m r s_{t}=\sigma c_{t}+\varphi n_{t}$, where $c_{t}$ denotes $(\log )$ consumption and where, once again, we ignore possible constant terms.

Given values for $\sigma$ (the constant relative risk aversion parameter) and $\varphi$ (which is just the inverse of the labor supply elasticity), the gap measure can be constructed as

$$
\operatorname{gap}_{t}=\sigma c_{t}+\varphi n_{t}-\left(y_{t}-n_{t}\right)
$$

Its components are then given by

$$
\begin{aligned}
\mu_{t}^{p} & \equiv p_{t}-m c_{t}^{n} \\
& =p_{t}-\left[w_{t}-\left(y_{t}-n_{t}\right)\right] \\
& =\left(y_{t}-n_{t}\right)-\left(w_{t}-p_{t}\right)
\end{aligned}
$$

and

$$
\begin{aligned}
\mu_{t}^{w} & \equiv\left(w_{t}-p_{t}\right)-m r s_{t} \\
& =\left(w_{t}-p_{t}\right)-\left(\sigma c_{t}+\varphi n_{t}\right)
\end{aligned}
$$

where $m c_{t}^{n}$ denotes the (log) nominal marginal cost, $p_{t}$ is the (log) price level and $w_{t}$ is the (log) nominal wage. 


\section{REFERENCES}

Baxter, Marianne and Robert King (1993): "Fiscal Policy in General Equilibrium,” American Economic Review 83, no. 3, 315-334.

Blanchard, Olivier and Roberto Perotti (2002), “An Empirical Characterization of the Dynamic Effects of Changes in Government Spending and Taxes on Output,” Quarterly Journal of Economics, vol CXVII, issue 4, 1329-1368.

Campbell, John Y. and N. Gregory Mankiw (1989): “Consumption, Income, and Interest Rates: Reinterpreting the Time Series Evidence,” in O.J. Blanchard and S. Fischer (eds.), NBER Macroeconomics Annual, 185-216, MIT Press

Christiano, Lawrence J. and Martin Eichenbaum (1992): “Current Real Business Cycle Theories and Aggregate Labor Market Fluctuations,” American Economic Review 82, 430-450.

Clarida, Richard, Jordi Galí, and Mark Gertler (2000): "Monetary Policy Rules and Macroeconomic Stability: Evidence and Some Theory," Quarterly Journal of Economics, vol. 105 , issue $1,147-180$.

Fatás, Antonio, and Ilian Mihov (2001): “The Effects of Fiscal Policy on Consumption and Employment,” INSEAD, mimeo.

Galí, Jordi, Mark Gertler, and J. David López-Salido (2005): “Markups, Gaps, and the Welfare Costs of Business Cycle Fluctuations,” CREI, mimeo.

Galí, Jordi, J. David López-Salido, and Javier Vallés (2003): “Understanding the Effects of Government Spending on Consumption,” ECB WP no. 339 
Galí, Jordi, and Roberto Perotti (2003) "Fiscal Policy and Monetary Policy Integration in Europe," Economic Policy, vol. 37, 533-572.

Keynes, John M. (1936): The General Theory of Employment, Interest and Money, Harcourt, Brace, and Company, Inc.

Prescott, Edward C. (1986): "Theory Ahead of Business Cycle Measurement," Quarterly Review 10, 9-22, Federal Reserve Bank of Minneapolis.

Rotemberg, Julio, and Michael Woodford (1999): “The Cyclical Behavior of Prices and Costs," in J. Taylor and M. Woodford (eds.), Handbook of Macroeconomics, vol 1B, North-Holland.

Stock, James, and Mark W. Watson (2002): "Has the Business Cycle Changed and Why?," NBER Macroeconomics Annual, MIT Press

Stock, James, and Mark W. Watson (2003): "Understanding Changes in International Business Dynamics," NBER Macroeconomics Annual 2003, MIT Press.

Taylor, John B. (1999): "An Historical Analysis of Monetary Policy Rules," in J.B. Taylor ed., Monetary Policy Rules, University of Chicago Press. 


\section{TABLE 1. Changes in Discretionary Fiscal Policy}

\begin{tabular}{|cccc|}
\hline & $\mathbf{1 9 8 0 - 1 9 9 1}$ & $\mathbf{1 9 9 2 - 2 0 0 2}$ & Change \\
Cross-Country Averages & & & \\
EMU & 0.25 & -0.23 & -0.48 \\
EU3 & -0.60 & -0.91 & -0.31 \\
OECD5 & -0.12 & -0.63 & -0.51 \\
Panel Estimates & & & \\
EMU & & & \\
EU3 & 0.17 & -0.08 & -0.25 \\
OECD5 & -0.09 & -0.76 & -0.67 \\
\hline
\end{tabular}

Note: displayed values are estimates of coefficient $\phi_{x}$ in equation (3) in the text. A negative (positive) sign represents a countercyclical (procyclical) fiscal policy, as discussed in the text. Source: Galí and Perotti (2003). 


\section{Table 2: Fighting Recessions with Fiscal Policy}

\begin{tabular}{|lccc|}
\hline \multicolumn{4}{|c|}{ Change in Structural Deficit / Change in Output Gap } \\
& Early 80s & Early 90s & Early 2000s \\
EMU & 0.33 & 0.27 & -0.24 \\
EU3 & 0.35 & -0.64 & -0.73 \\
OECD5 & 0.20 & -0.69 & -0.52 \\
\hline
\end{tabular}

Note: displayed values are the ratio of "cumulative changes in the structural deficit" to "cumulative changes in the output gap" over recession periods. A negative (positive) sign represents countercyclical (procyclical) fiscal policy, as discussed in the text. Source: Galí and Perotti (2003) 
Figure 1. The GGL Gap

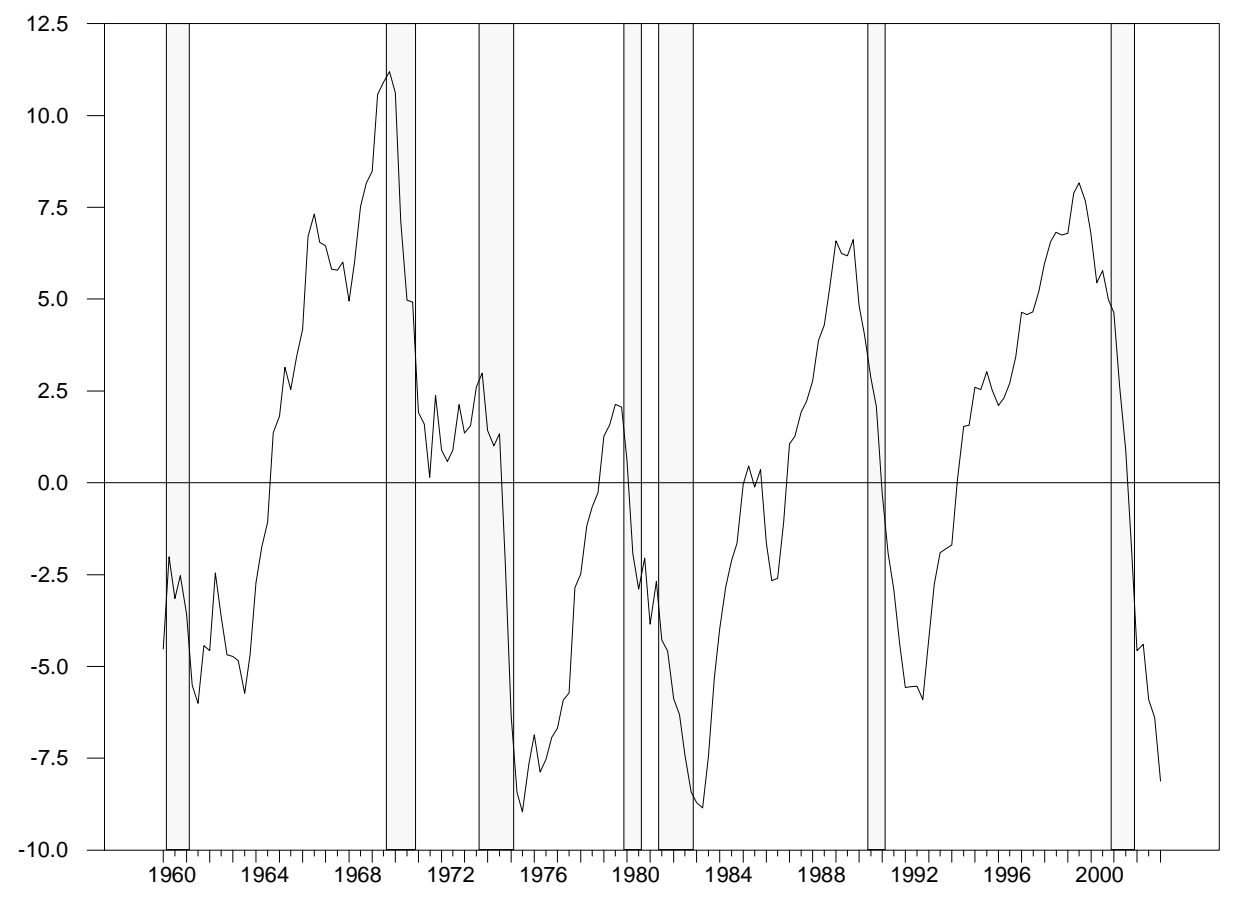

Source: Galí, Gertler, and López-Salido (2005) 